\title{
Viscoless microincision cataract surgery
}

Guy Sallet

Department of Opthamology, Aalsters Stedelijk Ziekenhuis, Belgium
Correspondence: Guy Sallet

Stationsstraat 20,9300 Aalst, Belgium

Tel +3253216839

Fax +3253214508

Email dr.sallet@pandora.be
Abstract: A cataract surgery technique is described in which incisions, continuous circular capsulorhexis and hydrodissection are made without the use of any viscoelastics. Two small incisions are created through which the different parts of the procedure can take place, maintaining a stable anterior chamber under continuous irrigation. Subsequent bimanual phacoemulsification can be done through these microincisions. At the end of the procedure, an intraocular lens can be inserted through the self-sealing incision under continuous irrigation. 50 consecutive cataract patients were operated on without the use of viscoelastics and then compared with a group of 50 patients who had been helped with viscoelastics. No difference in outcome, endothelial cell count or pachymetry was noted between the two groups. No intraoperative complication was encountered. Viscoless cataract surgery was a safe procedure with potential advantages.

Keywords: ophthalmic visco-surgical device, viscoless cataract surgery, microincision

\section{Introduction}

Ultrasound phacoemulsification with implantation of a foldable intraocular lens (IOL) has become the method of choice today in cataract surgery (Leaming 2004). The introduction of ophthalmic visco-surgical devices (OVDs) was a significant improvement, and OVDs are important tools in modern phacoemulsification surgery. They are used to reform and maintain a stable anterior chamber and capsular bag, and to safely perform continuous capsulorhexis and in-the-bag placement of IOLs. These devices protect the endothelium and can enhance pupil mydriasis at the same time.

There are some possible side effects of OVDs. Blockage of microincisions by OVDs can cause capsular bag distension during hydrodissection, which can cause posterior capsular rupture (Ota et al 1996). Excessive injection of OVDs forms a risk factor of floppy iris syndrome (Chang and Campbell 2005). Postoperative intraocular pressure spikes are well-known side effects of OVDs (Rainer et al 2001; Moser et al 2004; Yachimori et al 2004) and entrapped OVD in the capsular bag can cause early postoperative capsular block syndrome (Miyake et al 1998) or low grade endophtalmitis (Sholohov and Levartovsky 2005). Aspiration of OVD after lens implantation requires further surgical manipulation and surgery time (Auffarth et al 2004a, 2004b). New OVDs improve the protection of the corneal endothelium but increase the surgical cost at the same time (Kiss et al 2003).

Given these possible side effects of OVDs and the self-sealing way microincisions are constructed, viscoless cataract surgery is a possible option. A technique is presented performing microincision cataract surgery with ultrasound phacoemulsification and the implantation of a foldable IOL without the use of any viscoelastics.

\section{Surgical technique}

The procedure starts with the creation of two small self-sealing incisions of $1.2 \mathrm{~mm}$ into clear cornea approximately 70 degrees apart. The water tightness of these incisions is of particular importance to reduce the chance of outflow of aqueous out of the eye. Afterwards, an irrigating chopper is introduced into the anterior chamber 
with the balanced salt solution (BSS) bottle $100 \mathrm{~cm}$ above the patient's eye level under continuous irrigation. This provides a stable anterior chamber while introducing this instrument through the small incision. Once the irrigating chopper is in place, continuous circular capsulorhexis is performed through the second microincision using small incision capsulorhexis forceps (Figure1). Under continuous irrigation, the anterior capsule can be described as "floating" into the anterior chamber. The irrigating chopper maintains a stable anterior chamber and can be used to manipulate the anterior capsule for grasping and completing the capsulorhexis.

Hydrodissection is performed under continuous irrigation of the irrigating chopper. Once the nucleus can be easily rotated, phacoemulsification is started. Microincisions of $1.2 \mathrm{~mm}$ ensure a minimal outflow of BSS out of the eye. A drawback is the occasionally difficult insertion of the $0.9 \mathrm{~mm}$ sleeveless phacoemulsification needle through the microincision corneal tunnel. At this stage, the height of the BSS bottle is set to $120 \mathrm{~cm}$ above the eye level to ensure good filling of the eye throughout the whole procedure, minimizing the chance for surge or instability of the anterior chamber. Microincision phacoemulsification is performed by using a chopping technique or by dividing and conquering, depending on the hardness of the nucleus. Phacoemulsification is performed using small amounts of bursts $(30 \%, 50 \mathrm{msec})$, vacuum of $350 \mathrm{~mm}$ $\mathrm{Hg}$ and aspiration rate of $25 \mathrm{cc} / \mathrm{min}$ for sculpting or chopping, and $40 \mathrm{cc} / \mathrm{min}$ for quadrant removal using ultrasound-assisted phacoaspiration. This surgery was performed using the Alcon Legacy and Infiniti (Alcon Manufacturing, Ltd., Irvine, CA). After removal of the nucleus, bimanual I/A with capsular polishing is performed through the same microincisions. Bimanual I/A makes the removal of subincisional cortex easier and working through the nonleaking microincisions gives a deep anterior chamber with an open capsular bag.

Before insertion of a standard foldable IOL (AcrySof SN60AT; Alcon Labs, Hünenberg, Switzerland), one of the microincisions is widened to $2.6 \mathrm{~mm}$ under continuous

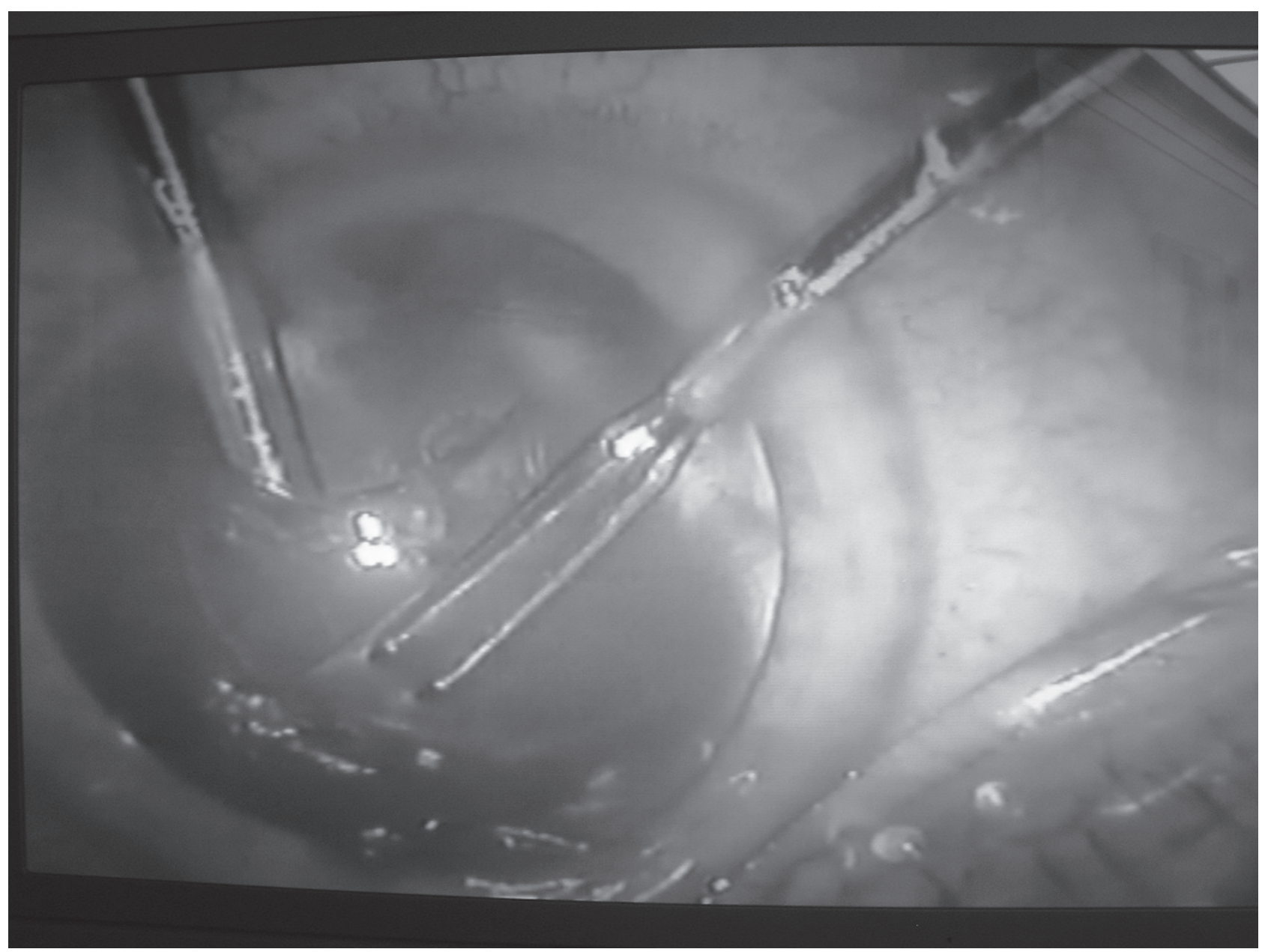

Figure I Continuous circular capsulorhexis under continuous irrigation with the irrigating chopper. 
irrigation. The BSS bottle is raised to $120 \mathrm{~cm}$ above the eye level to obtain a deep anterior chamber and capsular bag for widening the incision. The IOL is inserted under continuous irrigation of the irrigating I/A cannula with the Monarch II C-cartridge (Alcon Labs). The IOL is mounted in the cartridge after filling the cartridge with BSS. While inserting the IOL into the eye, the lip of the cartridge is set at the corneal tunnel and the IOL is slowly injected through the tunnel in the capsular bag (Figure 2). The IOL haptics are placed in the fornix of the capsular bag (Figure 3 ). While inserting the IOL inside the eye, care is taken that there is not too much outflow of BSS out of the eye. This could make the capsular bag narrower, increasing the chance of touching the posterior capsule. If the posterior capsule is touched, the IOL is lifted and introduced into the eye. The injector is withdrawn, and due to the self-sealing incision, the irrigating port of the bimanual I/A provides us with a wide capsular bag. This irrigating port can then be used to introduce the haptics in the capsular bag. The irrigating cannula is withdrawn from the eye and the microincisions are sealed by slight hydration of the wound.

\section{Study}

Two groups of 50 eyes with nuclear hardness grade I-III were compared regarding pre- and postoperative pachymetry, endothelial cell count as well as total surgery time. All eyes were given a full ophthalmologic examination. Besides cataract, no other pathology was noted. All eyes had a good dilatation of the pupil. Group 1 was operated on according to the above described surgical technique without the use of any OVD, group 2 with the use of OVD. In group 2, Viscoat ${ }^{\circledR}$ was used for capsulorhexis and Provisc ${ }^{\circledR}$ for implantation of the IOL. At the end of the procedure, OVD was aspirated out of the eye.

Endothelial cell count and pachymetry were done using the Topcon SP 200 specular microscope. A cluster of 30 cells were indicated in the centre of the cornea to count the average density of cells $/ \mathrm{mm}^{2}$. This was done at the pre-operative ophthalmologic examination and one month postoperatively.

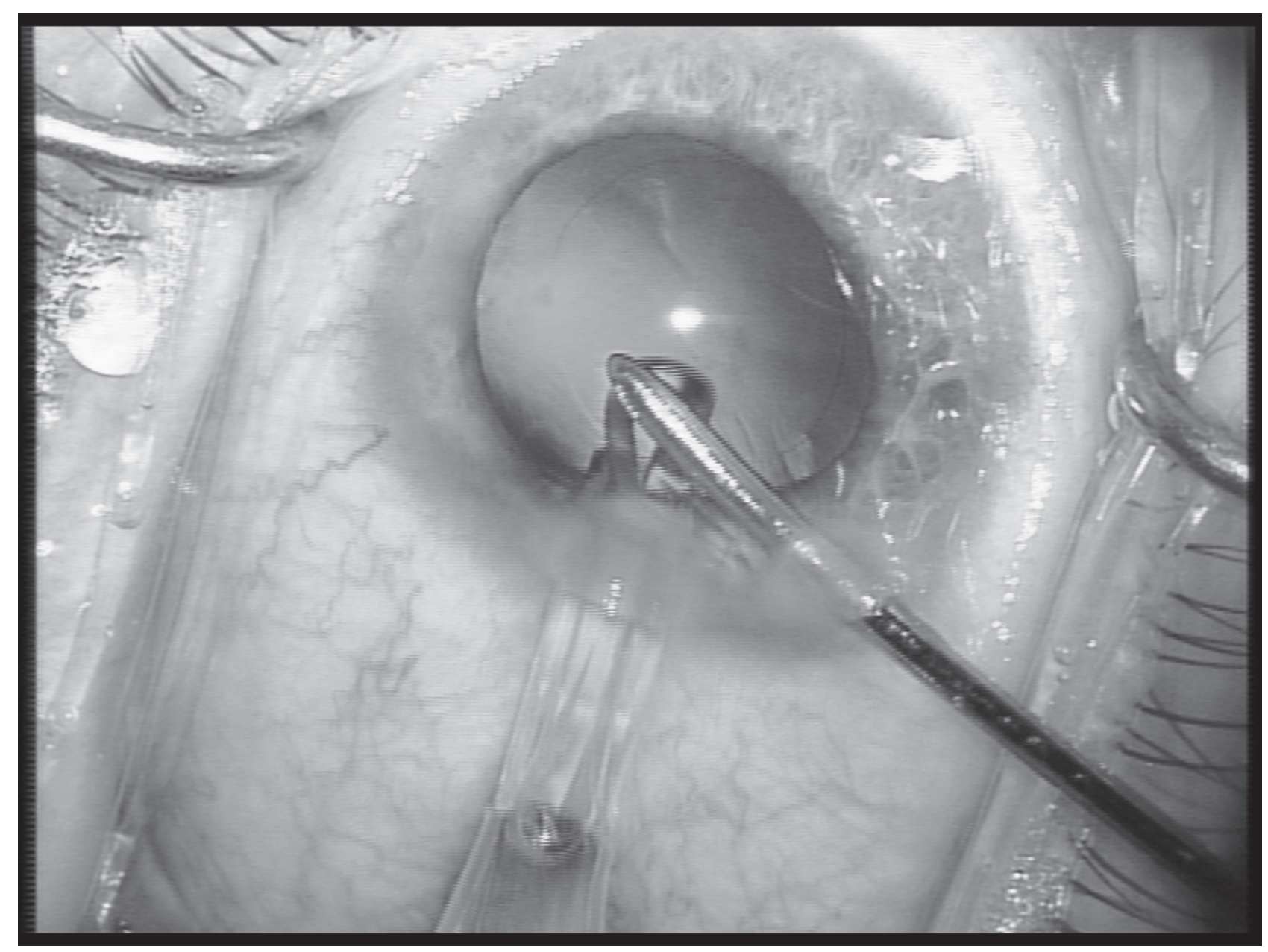

Figure 2 Placement of the tip of the injector at the $2.6 \mathrm{~mm}$ incision and injection of the $\mathrm{OOL}$ with the irrigation port of the bimanual I/A. 


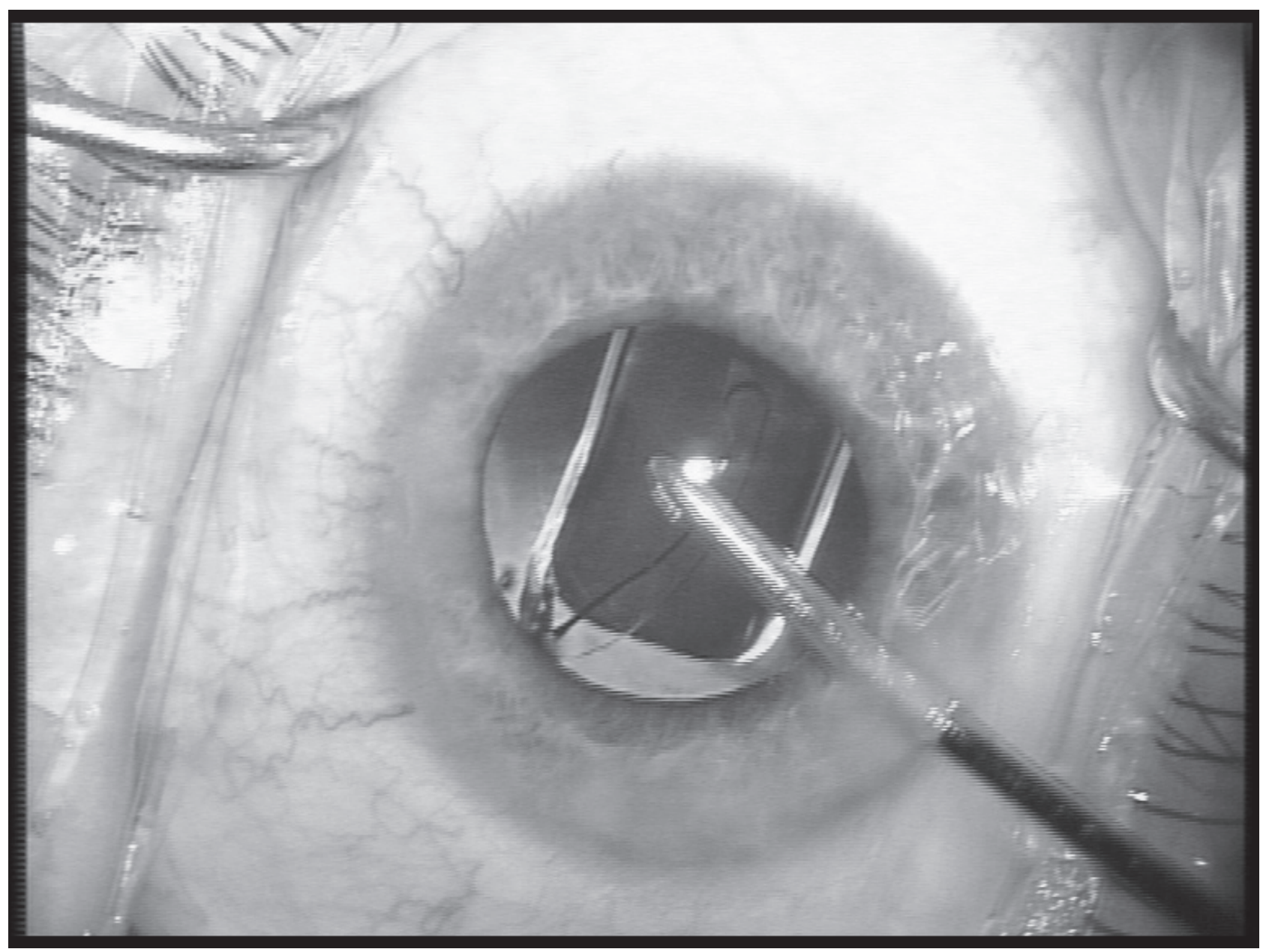

Figure 3 Placement of the IOL into the capsular bag under continuous irrigation.

\section{Results}

In 6 of the first 15 eyes in group 1, viscoelastics were needed for insertion of the IOL. All eyes recovered 20/25 vision or better 1 month postoperatively. No other intraoperative complication was encountered. Mean endothelial cell loss was 305 cells $/ \mathrm{mm}^{2}$ (range: $+176-789$ ) in group 1 and 382 cells $/ \mathrm{mm}^{2}$ (range: $+157-921$ ) in group 2 . The difference was statistically insignificant (student t-test $p=0.2874$ ).

Mean difference in pachymetry was $+0.68 \mu$ (range: $-20 \pm 22$ ) in group 1 and -0.01 (range: $-15.52 \pm 15.73$ ) in group 2 . Student t-test showed no statistically significant difference $(p=0.845)$. Mean surgery time was $11.5 \mathrm{~min}$ in group 1 and $13.1 \mathrm{~min}$ in group 2.

\section{Discussion}

The advantages of continuous anterior chamber infusion using an anterior chamber maintainer have been stressed by Blumenthal and colleagues (1994). Schipper (1996) presented a technique of phacoemulsification and implantation of an IOL with the anterior chamber maintainer and without the use of visco-elastic substances. Our technique uses the advantages of continuous anterior chamber infusion and merges it with microincision bimanual phacoemulsification. The use of an irrigating chopper and bimanual I/A eliminates the need for an anterior chamber maintainer and a third incision. There was a definite learning curve as in the first 15 eyes while additional OVD for lens implantation was necessary in 6 eyes. The different steps for this technique without the use of OVD demand some surgical dexterity. This might be the reason we had a small capsulorhexis size in 4 eyes. However, injection of OVD at any stage of the procedure converts the surgery to routine cataract surgery. As some eyes showed corneal edema the first day after surgery, the question rises as to whether the absence of protective OVD could cause endothelial damage. A study on endothelial cell count pre- and postoperatively showed no statistically significant increase in endothelial cell loss, nor in pachymetry, compared with standard phacoemulsification. In a recent report by Milla and 
colleagues (2005), no additional corneal endothelial damage was found using continuous anterior chamber infusion during phacoemulsification.

A similar technique was reported by Galan (2005) without the use of viscoelastics, and had a success rate of $60 \% \mathrm{He}$ performed phacoemulsifiaction with $1.6 \mathrm{~mm}$ incisions and an enlargement to $3 \mathrm{~mm}$ for IOL implantation. The higher success rate in our technique could be due to the narrower incisions of $1.2 \mathrm{~mm}$ and $2.6 \mathrm{~mm}$ for IOL implantation, rendering a more stable anterior chamber throughout the procedure.

There are additional clinical advantages of viscoless cataract surgery:

1) Intraocular pressure spikes are less likely to occur, as no viscoelastics can block the outflow channels. Schipper and colleagues (2000) presented a series of 33 patients, on whom they performed cataract surgery without viscoelastics using an anterior chamber maintainer. Patients in this study showed less intraocular pressure elevation. An anterior chamber maintainer for the introduction of foldable IOLs has been described, with the potential for fewer intraocular pressure spikes (Shingleton and Mitrev 2001). Therefore, cataract surgery without the use of viscoelastics can be of value in glaucoma patients.

2) As no injection or aspiration of viscoelastics is needed, the procedure can shorten surgery time. In this study, mean surgery time was 1.6 minutes less than conventional phacoemulsification with the use of OVD.

3) Hydrodissection under continuous irrigation lessens the chance of blocking the microincisions and subsequent capsular bag distension, and lowers the risk of floppy iris syndrome as the result of a sudden decompression of the anterior chamber.

4) The absence of viscoelastics during the procedure reduces cataract surgery costs substantially. In Belgium, costs of OVD are approximately 100 Euro per case.

5) There is always an easy conversion to the use of viscoelastics at any stage of the procedure and to progress with a conventional phacoemulsification procedure.

In conclusion, viscoless microincision cataract surgery was a safe and effective procedure. Due to the additional advantages, further attention to this procedure is merited, in order to make microincision cataract surgery easier and more cost effective.

\section{Disclosure}

The author reports no conflicts of interest.

\section{References}

Auffarth GU, Holzer MP, Vissesook N, et al. 2004a. Removal times and techniques of a viscoadaptive ophthalmic viscosurgical device. $J$ Cataract Refract Surg, 30:879-83.

Auffarth GU, Holzer MP, Vissesook N, et al. 2004b. Removal times for a dispersive and a cohesive ophthalmic viscosurgical device correlated with intra-ocular lens material. J Cataract Refract Surg, 30:2410-14.

Blumenthal M, Assia EI, Chen V, et al. 1994. Using an anterior chamber maintainer to control intra-ocular pressure during phaco-emulsification. $J$ Cataract Refract Surg, 20:93-6.

Chang DF, Campbell JR. 2005. Intraoperative floppy iris syndrome associated with tamsulosin. J Cataract Refract Surg, 31:664-73.

Galan A. 2005. Phaco-emulsification without the use of visco-elastic devices. Ocular Surgery News. Europe/Pacific Edition, April 2005.

Kiss B, Findl O, Menapce R, et al. 2003. Corneal endothelial cell protection with a dispersive viscoelastic material and an irrigating solution during phacoemulsification : low-cost versus expensive combination. $J$ Cataract Refract Surg, 29:733-40.

Leaming DV. 2004. Practice styles and preferences of ASCRS members 2003 Survey. J Cataract Refract Surg, 30:892-900.

Milla E, Verges C, Cipres M. 2005. Corneal endothelium evaluation after phacoemulsification with continuous anterior chamber infusion. Cornea, 24:278-82.

Miyake K, Ota I, Ichihashi S, et al. 1998. New classification of capsular block syndrome. J Cataract Refract Surg, 24:1230-4.

Moser CL, Martin-Baranera M, Garat M, et al. 2004. Corneal edema and intra-ocular pressure after cataract surgery: randomized comparison of Healon5 and Amvisc Plus. J Cataract Refract Surg, 30:2359-65.

Ota I, Myake S, Miyake K. 1996. Dislocation of the lens nucleus into the vitreous cavity after standard hydrodissection. Am J Ophthalmol, 121:706-8.

Rainer G, Menapace R, Findl O, et al. 2001. Intra-ocular pressure rise after small incision cataract surgery: a randomised intraindividual comparison of two dispersive viscoelastic agents. Br J Ophthalmol, 85:139-42.

Schipper I, Lechner A, Senn P. 2000. Intraocular pressure after phacoemulsification and implantation of silicone haptic intraocular lenses without viscoelastics. Klin Monatsbl Augenheilkd 2000; 216: 96-98

Schipper I. 1996. Implantation of a Staar silicone intraocular lens with the anterior chamber maintainer. J Cataract Refract Surg, 22:23-6.

Shingleton BJ, Mitrev PV. 2001. Anterior chamber maintainer versus viscoelastic material for intraocular lens implantation: case-control study $J$ Cataract Refract Surg, 27:711-14.

Sholohov G, Levartovsky S. 2005. Retained ophthalmic viscosurgical device material in the capsular bag 6 months after phacoemulsification. $J$ Cataract Refract Surg, 31:627-9.

Yachimori R, Matsuura T, Hayashi K, Hayashi H. 2004. Increased intraocular pressure and corneal endothelial cell loss following phacoemulsification surgery. J Cataract Refract Surg, 35:453-9. 
